\title{
1 Whole genome genetic variation and linkage disequilibrium in a diverse collection of
}

\section{Listeria monocytogenes isolates}

3 Swarnali Louha ${ }^{1}$, Richard J. Meinersmann ${ }^{2}$, Travis C. Glenn ${ }^{1,3}$

$4{ }^{1}$ Institute of Bioinformatics, University of Georgia, Athens, GA, USA.

$5{ }^{2}$ USDA Agricultural Research Service, U.S. National Poultry Research Center, Athens, GA, 6 USA.

$7{ }^{3}$ Department of Environmental Health Science, University of Georgia, Athens, GA, USA.

8

$9 *$ Corresponding author

10 E-mail: s150708@uga.edu (SL) 


\section{Abstract}

12 We performed whole-genome multi-locus sequence typing for 2554 genes in a large and

13 heterogenous panel of 180 Listeria monocytogenes strains having diverse geographical and

14 temporal origins. The subtyping data was used for characterizing genetic variation and

15 evaluating patterns of linkage disequilibrium in the pan-genome of L. monocytogenes. Our

16 analysis revealed the presence of strong linkage disequilibrium in L. monocytogenes, with $\sim 99 \%$

17 of genes showing significant non-random associations with a large majority of other genes in the

18 genome. Twenty-seven loci having lower levels of association with other genes were considered

19 to be potential "hot spots" for horizontal gene transfer (i.e., recombination via conjugation,

20 transduction, and/or transformation). The patterns of linkage disequilibrium in L. monocytogenes

21 suggest limited exchange of foreign genetic material in the genome and can be used as a tool for

22 identifying new recombinant strains. This can help understand processes contributing to the

23 diversification and evolution of this pathogenic bacteria, thereby facilitating development of

24 effective control measures. 


\section{Introduction}

The bacterial genome is a dynamic structure. Characterizing patterns of genomic

27 variation in bacterial pathogens can provide insights into the forces shaping their biology and

28 evolutionary history (Zwick et al 2011). Homologous recombination is an important driver of

29 evolution and increases the adaptive potential of bacteria by allowing variation to be tested

30 across multiple genomic backgrounds (Yahara et al. 2015). Recombination is mediated by three

31 mechanisms; transformation, transduction, and conjugation, and the availability and efficacy of

32 these mechanisms and their biological consequences play a major role in determining the

33 frequency of recombination in a bacterial population (Feil and Spratt 2001, Zwick et al 2011).

34 Recombination is variably distributed in bacterial genomes, with some sites in the genome

35 recombining at a higher or lower frequency than the genomic average, known as hot spots and

36 cold spots respectively (Steiner and Smith 2005). Evidence for recombination and its effect on

37 genomic variation can be obtained by detecting patterns of non-random association of genotypes

38 at different loci within a given population, termed as linkage disequilibrium (Feil and Spratt

39 2001, Zwick et al 2011). Various methods for detecting linkage disequilibrium have been used to

40 study the extent of genetic recombination shaping the population structures of several bacterial

41 species (Smith et al. 1993, Zwick et al. 2011, Takuno et al. 2012, Vigué and Eyre-Walker 2019).

42 Listeria monocytogenes, known for causing life-threatening infections in animals and

43 human populations at risk, is one of the bacterial species having the lowest rate of homologous

44 recombination. Genetic diversity in this species is mainly driven by the accumulation of

45 mutations over time, with alleles five times more likely to change by mutation than by

46 recombination (Ragon et al. 2008). L. monocytogenes is generally considered to have a clonal

47 genetic structure (Piffaretti et al. 1989, Wiedmannn et al. 1997). The population structure of this 
bacteria consists of 4 evolutionary lineages (I, II, III and IV) and recombination has been

49 observed between isolates of different lineages; suggesting that although recombination is rare in

L. monocytogenes, this species is not completely clonal (den Bakker et al. 2008, Dunn et al.

512009 , Ragon et al. 2008). Interestingly, homologous recombination is not equally frequent

52 among isolates of different lineages, with lineages II, III and IV showing higher rates of

53 recombination and lower degree of sequence similarity than lineage I (Meinersmann et al. 2004,

54 den Bakker et al. 2008, Orsi et al. 2008, Kuenne et al. 2013).

Whole-genome sequencing studies have shown that L. monocytogenes genomes are

56 highly syntenic in their gene content and organization, with a majority of gene-scale differences

57 occurring in the accessory genome and accumulated in a few hypervariable hotspots, prophages,

58 transposons, scattered unique genes and genetic islands encoding proteins of unknown functions

59 (Nelson et al. 2004, Hain et al. 2007, den Bakker et al. 2010, 2013, Kuenne et al. 2013). Several

60 other studies have detected evidence of recombination using a few genes (den Bakker et al. 2008,

61 Cantinelli et al. 2013, Ragon et al. 2008) and indicated the presence of significant linkage

62 disequilibrium in L. monocytogenes (Call et al. 2003, Salcedo et al. 2003). However, these

63 studies used a limited number of L. monocytogenes isolates and evaluated recombination present

64 in a small fraction of the genome, mostly made up of house-keeping genes, which are assumed to

65 be under negative selection and less subject to homologous recombination.

Prior to the advent of next-generation sequencing technologies, multi locus enzyme

67 electrophoresis (MLEE), was used for generating large data sets for the statistical analysis of

68 bacterial populations. MLEE differentiates organisms by assessing the relative electrophoretic

69 mobilities of intracellular enzymes and indexes allelic variation in multiple chromosomal genes

70 (Mallik 2014). MLEE has been successfully used for studying the extent of linkage 
71 disequilibrium in a variety of bacterial species (Piffaretti et al. 1989, Maynard Smith et al. 1993,

72 O'Rourke and Stevens 1993). With the easy and cheap availability of sequencing data in the last

73 decade, MLEE has been replaced with an analogous technique called MLST (multi locus

74 sequence typing) for subtyping bacterial genomes (Salcedo et al. 2003, Moura et al. 2017). We

75 recently provided an approach that can generate whole-genome MLST (wgMLST) based

76 characterization of L. monocytogenes isolates from whole-genome sequencing data (Louha et al.

77 2020). In this study, we use this wgMLST-based approach for characterizing genomic variation

78 and assessing genome-wide patterns of linkage disequilibrium in a large collection of $L$.

79 monocytogenes isolates obtained from diverse ecological niches.

\section{Materials and methods}

\section{L. monocytogenes isolate selection}

We selected a large and diverse panel of 180 L. monocytogenes isolates collected from

84 different ecological communities (File S1). This set included (i) 20 isolates each from food, food

85 contact surfaces (FCS), manure, milk, clinical cases, soil, and ready-to-eat (RTE) products

86 obtained from the NCBI Pathogen Detection database and, (ii) 20 isolates from water and

87 sediment samples in the South Fork Broad River watershed located in Northeast Georgia and 20

88 isolates from effluents from poultry processing plants (EFPP), provided by the USDA and FSIS.

\section{Whole-genome multi-locus sequence typing (wgMLST)}

90 Whole-genome sequencing data for the 180 L. monocytogenes isolates were processed

91 using Haplo-ST (Louha et al. 2020) for allelic profiling of 2554 genes per isolate. Illumina

92 whole-genome sequencing reads obtained as previously described (File S1) were trimmed to 
93 remove all bases with a Phred quality score of $<20$ from both ends and filtered such that $90 \%$ of

94 bases in the clean reads had a quality of at least 20. After trimming and filtering, all remaining

95 reads with lengths of $<50 \mathrm{bp}$ were filtered out. The cleaned reads were assembled into allele

96 sequences with YASRA (Ratan 2009) by mapping to reference genes and provided wgMLST

97 profiles with BIGSdb-Lm (available at http://bigsdb.pasteur.fr/listeria).

98 Analysis of Linkage Disequilibrium

First, the raw wgMLST profiles were filtered to remove paralogous loci and genes were

100 ordered according to their genomic position in the L. monocytogenes reference strain EGD-e

101 (NCBI accession number NC_003210.1). Next, new alleles not defined in the BIGSdb-Lm

102 database and reported as 'closest matches' to existing alleles in BIGSdb- $\mathrm{Lm}$ were assigned

103 custom allele ID's with in-house Python scripts. The wgMLST profiles were further filtered to

104 retain loci with $<5 \%$ missing data. The remaining loci were used to evaluate linkage

105 disequilibrium (LD) between all pairs of loci with Arlequin v3.5.2 (Excoffier and Lischer 2010).

106 LD tests for the presence of significant statistical association between pairs of loci and is based

107 on an exact test. The test procedure is analogous to Fisher's exact test on a two-by-two

108 contingency table but extended to a contingency table of arbitrary size (Slatkin 1994). For each

109 pair of loci, first a contingency table is constructed. The $k_{1} \times k_{2}$ entries of this table are the

110 observed haplotype frequencies, with $k_{1}$ and $k_{2}$ being the number of alleles at locus 1 and locus 2 ,

111 respectively. The LD test consists in obtaining the probability of finding a table with the same

112 marginal totals and which has a probability equal or less than that of the observed contingency

113 table. Instead of enumerating all possible contingency tables, a Markov chain is used to explore

114 the space of all possible tables. To start from a random initial position in the Markov chain, the

115 chain is explored for a pre-defined number of steps (the dememorization phase), such as to allow 
116 the Markov chain to forget its initial phase and make it independent from its starting point. The

$117 P$-value of the test is then taken as the proportion of the visited tables having a probability

118 smaller or equal to the observed contingency table. In our analysis, we used 100,000 steps of

119 Markov chain to test the $P$-value of the LD test and 10,000 dememorization steps to reach a

120 random initial position on the Markov chain. The significance level of the LD test was set at a $P$ -

121 value of 0.05

122 Assessment of genetic diversity

123 Genetic diversity between L. monocytogenes isolates collected from the different

124 ecological niches listed as the isolate sources (File S1) was computed with pairwise $\mathrm{F}_{\mathrm{ST}}$ 's in

125 Arlequin. $\mathrm{F}_{\mathrm{ST}}$ measures the proportion of the variance in allele frequencies attributable to

126 variation between populations (Charlesworth and Charlesworth 2010) and has a history of being

127 used as a measure of the level of differentiation between populations in population genetics.

128 Fifty thousand permutations were used to test the significance of the genetic distances at a

129 significance level of 0.05.

130 The AMOVA procedure in Arlequin was used to compute the pairwise differences in

131 allelic content between isolate wgMLST profiles as a matrix of Euclidean squared distances.

132 This distance matrix was used to compute a minimum spanning tree (MST) between all isolates.

133 The MST was visualized and annotated with iTOL v3 (Letunic and Bork 2016). For better

134 visualization, the MST was converted to circular format and annotations for the source of

135 isolates were displayed in outer external rings. 


\section{Results}

139 isolates obtained from 9 different source populations. For each isolate, allele sequences were 140 assembled for 2554 genes and provided allele ID's based on the unified nomenclature available

141 in the BIGSdb- $L m$ database (File S2). This dataset was filtered to remove 133 paralogous loci

142 identified by Haplo-ST and all loci with > 5\% missing data (alleles not assigned ID's by Haplo-

143 ST), and the remaining 2233 loci (File S3) were ordered according to their position in the $L$.

144 monocytogenes reference genome EGD-e. Figure 1 shows the minimum spanning tree of the 180

145 isolates inferred from allelic differences in the wgMLST profiles. Two results are apparent. First,

146 we see a long branch (red) containing a majority of isolates obtained from soil and manure

147 clustered together, which suggests the origin of these strains from a common ancestor.

148 Interestingly, 3 clinical strains are also found in this cluster. Secondly, a large number of food-

149 related isolates ( $\sim 51 \%$, obtained from food, FCS, RTE products and EFPP) clustered together in

150 a single branch of the tree (blue) with short branch-lengths to the tips, suggesting that these

151 strains are closely related to each other. Although this is expected, it is interesting to find a few

152 strains obtained from clinical cases, river water and milk in this cluster. The presence of isolates

153 from unrelated ecological communities could be due to the technique used for constructing the

154 dendrogram, which groups isolates based on pairwise differences in allelic content between

155 isolate wgMLST profiles rather than characterizing differences between all variants in nucleotide

156 sequences.

158 Figure 1: Patterns of genetic differentiation in the 180 L. monocytogenes isolates. Minimum

159 spanning tree based on a distance matrix measuring pairwise differences in allelic content 
160 between isolate wgMLST profiles. The isolation source of each isolate is indicated with colors

161 on the outer ring. Majority of the isolates sampled from soil and manure cluster together in a

162 distant branch (red), suggesting their recent emergence from a common ancestor. A large number

163 of food-related isolates cluster together in a single branch of the tree (blue), suggesting their

164 close relatedness.

167 from different ecological communities (Table 1) shows that isolates obtained from soil and

168 manure show considerable genetic differentiation from isolates belonging to other communities,

169 with the exception of isolates obtained from clinical cases. Secondly, isolates from the EFPP-

170 RTE pairing has lower $\mathrm{F}_{\mathrm{ST}}$ than EFPP pairing from all other locations. Thirdly, the clustering

171 dendrogram (Fig 1) and $\mathrm{F}_{\mathrm{ST}}$ test are supportive of each other in that isolates from RTE, FCS and

172 food are not distinguished as separate populations.

174 Table 1: Pairwise genetic distances $\left(\mathrm{F}_{\mathrm{ST}}\right)$ between groups of $\boldsymbol{L}$. monocytogenes strains

175 isolated from nine different ecological niches.

\begin{tabular}{|c|c|c|c|c|c|c|c|c|}
\hline & clinical & food & FCS & manure & milk & $\begin{array}{c}\text { RTE } \\
\text { product }\end{array}$ & soil & $\begin{array}{c}\text { River } \\
\text { water }\end{array}$ \\
\hline clinical & 0 & & & & & & & \\
\hline food & $0.051^{*}$ & 0 & & & & & & \\
\hline FCS & $0.062^{*}$ & 0.015 & 0 & & & & & \\
\hline manure & $0.067^{*}$ & $0.126^{*}$ & $0.137^{*}$ & 0 & & & & \\
\hline milk & $0.047^{*}$ & $0.047^{*}$ & $0.073^{*}$ & $0.124^{*}$ & 0 & & & \\
\hline $\begin{array}{c}\text { RTE } \\
\text { product }\end{array}$ & $0.09^{*}$ & 0.004 & 0.007 & $0.159^{*}$ & $0.069^{*}$ & 0 & & \\
\hline soil & $0.064^{*}$ & $0.11^{*}$ & $0.124^{*}$ & $0.019^{*}$ & $0.104^{*}$ & $0.135^{*}$ & 0 & \\
\hline $\begin{array}{c}\text { River } \\
\text { water }\end{array}$ & $0.094^{*}$ & $0.091^{*}$ & $0.107^{*}$ & $0.153^{*}$ & $0.069^{*}$ & $0.092^{*}$ & $0.113^{*}$ & 0 \\
\hline EFPP & $0.165^{*}$ & $0.157^{*}$ & $0.137^{*}$ & $0.221^{*}$ & $0.146^{*}$ & $0.076^{*}$ & $0.189^{*}$ & $0.13^{*}$ \\
\hline
\end{tabular}


$176 \quad(* \mathrm{P}<0.05)$

We investigated LD between pairs of genes in the genome using an exact test, which

178 measures non-random associations between alleles at two loci based on the difference between

179 observed and expected allele frequencies. As expected, most genes pairs $(\sim 97 \%)$ in the genome

180 of L. monocytogenes show significant LD among pairs of alleles (Fig 2, File S4). A majority of

181 genes $(2205$ of of $2233, \sim 99 \%)$ were found to be at LD with at least $90 \%$ of other genes in the

182 genome (File S5). Of the remaining 27 genes $(\sim 1 \%)$ that were at LD with $<90 \%$ of genes (Table

183 2), 10 genes were found to be at LD with $<50 \%$ of genes. A single locus, lmo0046, was at LD

184 with only 19 other genes.

186 Figure 2: Heatmap of the extent of LD in the genome of L. monocytogenes. Genes are

187 ordered according to their genomic positions in the L. monocytogenes reference strain EGD-e

188 along the $\mathrm{x}$ and $\mathrm{y}$ axis (for gene names see File S4). A majority of genes show significant LD in

189 the genome (indigo), while few genes are at linkage equilibrium (yellow).

191 Table 2: Genes at LD with $<90 \%$ of genes in the genome of $L$. monocytogenes, thus

192 showing significant evidence for horizontal genetic transfer.

\begin{tabular}{|c|c|c|c|c|c|}
\hline $\begin{array}{c}\text { Gene } \\
\text { name }\end{array}$ & $\begin{array}{c}\text { Number } \\
\text { of } \\
\text { genes } \\
\text { at LD }\end{array}$ & $\begin{array}{c}\text { Percentage } \\
\text { of genes at } \\
\text { LD }\end{array}$ & $\begin{array}{c}\text { Location in the } \\
\text { chromosome of } \\
\text { EGD-e (bp) }\end{array}$ & $\begin{array}{c}\text { Location in } \\
\text { core/accessory } \\
\text { genome* }\end{array}$ & Function \\
\hline Imo0046 & 19 & 0.85 & $50514 . .50753$ & core & $\begin{array}{c}\text { small subunit } \\
\text { ribosomal } \\
\text { protein S18 }\end{array}$ \\
\hline Imo2624 & 185 & 8.289 & $2701254 . .2701445$ & core & $\begin{array}{c}\text { large subunit } \\
\text { ribosomal } \\
\text { protein L29 }\end{array}$ \\
\hline Imo2856 & 215 & 9.63 & $2943569 . .2943703$ & accessory & large subunit \\
\hline
\end{tabular}




\begin{tabular}{|c|c|c|c|c|c|}
\hline & & & & & $\begin{array}{c}\text { ribosomal } \\
\text { protein L34 }\end{array}$ \\
\hline Imo1364 & 239 & 10.71 & $1387014 . .1387214$ & accessory & $\begin{array}{l}\text { Cold shock } \\
\text { protein }\end{array}$ \\
\hline Imo1469 & 454 & 20.34 & $1501881 . .1502054$ & core & $\begin{array}{c}\text { small subunit } \\
\text { ribosomal } \\
\text { protein S21 }\end{array}$ \\
\hline Imo2616 & 458 & 20.52 & 2697988..2698347 & accessory & $\begin{array}{c}\text { large subunit } \\
\text { ribosomal } \\
\text { protein L18 }\end{array}$ \\
\hline Imo1816 & 484 & 21.69 & 1890951..1891139 & core & $\begin{array}{c}\text { large subunit } \\
\text { ribosomal } \\
\text { protein L28 }\end{array}$ \\
\hline Imo0248 & 576 & 25.81 & 265029..265454 & accessory & $\begin{array}{l}\text { large subunit } \\
\text { ribosomal } \\
\text { protein L11 }\end{array}$ \\
\hline Imo1335 & 880 & 39.43 & $1363826 . .1363975$ & core & $\begin{array}{c}\text { large subunit } \\
\text { ribosomal } \\
\text { protein L33 }\end{array}$ \\
\hline $\begin{array}{c}\text { inlH } \\
(\operatorname{Imo0263)}\end{array}$ & 1006 & 45.07 & $284365 . .286011$ & accessory & internalin $\mathrm{H}$ \\
\hline $\begin{array}{c}\text { cwhA } \\
(\text { Imo0582) }\end{array}$ & 1223 & 54.79 & 618932..620380 & accessory & $\begin{array}{c}\text { Invasion } \\
\text { associated } \\
\text { secreted } \\
\text { endopeptidase }\end{array}$ \\
\hline Imo2047 & 1377 & 61.69 & 2130228..2130401 & accessory & $\begin{array}{c}\text { large subunit } \\
\text { ribosomal } \\
\text { protein L32 }\end{array}$ \\
\hline Imo2628 & 1508 & 67.56 & $2702909 . .2703187$ & accessory & $\begin{array}{c}\text { small subunit } \\
\text { ribosomal } \\
\text { protein S19 }\end{array}$ \\
\hline Imo2614 & 1580 & 70.79 & 2697267..2697446 & core & $\begin{array}{l}\text { large subunit } \\
\text { ribosomal } \\
\text { protein L30 }\end{array}$ \\
\hline Imo0758 & 1606 & 71.95 & 783901..784788 & core & $\begin{array}{c}\text { Hypothetical } \\
\text { protein }\end{array}$ \\
\hline Imo0514 & 1699 & 76.12 & $547520 . .549337$ & accessory & Internalin \\
\hline Imo0305 & 1709 & 76.57 & 329923..330999 & core & $\begin{array}{c}\text { L-allo-threonine } \\
\text { aldolase }\end{array}$ \\
\hline Imo0659 & 1771 & 79.35 & $699410 . .700306$ & accessory & $\begin{array}{c}\text { Transcriptional } \\
\text { regulator }\end{array}$ \\
\hline Imo2206 & 1791 & 80.24 & $2294555 . .2297155$ & accessory & $\begin{array}{c}\text { Heat shock } \\
\text { proteins }\end{array}$ \\
\hline
\end{tabular}




\begin{tabular}{|c|c|c|c|c|c|}
\hline Imo0756 & 1797 & 80.51 & 781896..782801 & core & $\begin{array}{c}A B C \\
\text { Transporters }\end{array}$ \\
\hline Imo0865 & 1859 & 83.29 & $903837 . .905510$ & core & $\begin{array}{c}\text { Amino sugar } \\
\text { and nucleotide } \\
\text { sugar } \\
\text { metabolism }\end{array}$ \\
\hline Imo2014 & 1888 & 84.59 & 2088797..2091454 & accessory & $\begin{array}{c}\text { Glycan } \\
\text { biosynthesis } \\
\text { and metabolism }\end{array}$ \\
\hline Imo1611 & 1904 & 85.3 & $1654902 . .1655975$ & core & Aminopeptidase \\
\hline $\begin{array}{c}\text { inlE } \\
(\operatorname{Imo0264)}\end{array}$ & 1913 & 85.71 & $286219 . .287718$ & accessory & Internalin E \\
\hline Imo1839 & 1925 & 86.25 & 1916166..1917452 & accessory & $\begin{array}{c}\text { Electrochemical } \\
\text { potential-driven } \\
\text { transporters }\end{array}$ \\
\hline Imo2179 & 1968 & 88.17 & $2264772 . .2268230$ & accessory & $\begin{array}{l}\text { Peptidoglycan } \\
\text { binding protein }\end{array}$ \\
\hline $\begin{array}{c}\text { inlB } \\
(\operatorname{Imo0434)})\end{array}$ & 1981 & 88.75 & $457021 . .458913$ & accessory & Internalin B \\
\hline
\end{tabular}

194 MLST scheme developed by the Institut Pasteur (Moura et al. 2016 Nat Microbiol 2: 16185).

\section{Discussion}

Our dataset reveals the presence of strong LD in the genome of L. monocytogenes.

198 Among the 2233 genes tested for LD, 2205 genes (approx. 99\%) were found to have pairwise

199 LD with a majority of other genes (90\%) in the genome. High levels of LD can not only arise in

200 highly clonal bacterial populations with low rates of recombination, but may also be temporarily

201 present in bacteria with 'epidemic' population structures, in which high recombination rates

202 randomize association between alleles, but adaptive clones emerge and diversify over the short-

203 term (Smith et al. 1993, Feil and Spratt 2001). Because Listeria has a clonal genetic structure, it

204 is difficult to see how this high level of LD can arise except as a consequence of low rates of 
recombination. This is consistent with studies which report recombination in chromosomal genes as an infrequent event in natural populations of L. monocytogenes (Piffaretti et al. 1989, Ragon et al. 2008). Because the extent of genetic linkage is a useful index to the horizontal transfer occurring within a species and can be presented as direct evidence for recombination (Feil et al. 2001), the remaining $\sim 1 \%$ of genes (Table 2 ) that were at LD with $<90 \%$ of genes can be

210 described as "hot spots" for the gain of horizontally acquired information. The extensive linkage

211 disequilibrium that we describe in L. monocytogenes is in sharp contrast to other pathogenic

212 bacteria that are naturally competent for transformation and recombine frequently to give rise to

213 either weakly clonal or panmictic population structures (Duncan et al. 1994, Suerbaum et al.

214 1998, Al Suwayyid et al. 2018).

215 The L. monocytogenes pan-genome is highly conserved but open to limited acquisition of

216 foreign DNA or genetic variability through evolutionary forces such as mutation, duplication or

217 recombination (Kuenne et al. 2013). Evidence for homologous recombination between closely

218 related strains of L. monocytogenes has been detected by multiple studies, however, non-

219 homologous recombination seems to be rare (Orsi et al. 2008, Dunn et al. 2009, Nightingale et

220 al. 2005). Although recombination via conjugation and generalized transduction has been

221 reported in L. monocytogenes (Flamm et al. 1984, Lebrun et al. 1992, Hodgson 2000), and most

222 competence related genes are present in all Listeria genomes (Buchrieser 2007), natural

223 competence or induced competence under laboratory conditions has not been observed in $L$.

224 monocytogenes (Borezee et al. 2000, Glaser et al. 2001). This lack of competence may partially

225 explain the low levels of gene acquisition from external gene pools. Limited gene acquisition

226 may also be facilitated by defense systems for foreign DNA/mobile elements such as restriction- 
modification and/or CRISPR systems, both of which have been shown to restrict horizontal gene

228

229

230

231

232

233

234

235

236

237

238

239

240

241

242

243

244

245

246

247

248

249

transfer in other bacterial genera (den Bakker et al. 2010).

The frequency of recombination in L. monocytogenes differs considerably in different

regions of the genome and between isolates of different lineages (den Bakker et al. 2008, 2013).

This may arise from differences in selective pressures in the environment and varying degrees of

horizontal gene transfer. Several comparative genomic studies report a clustered distribution of

accessory genes on the right replichore of the L. monocytogenes genome (approx. $500 \mathrm{~Kb}$ in the

first $65^{\circ}$ ), indicating an area of high genome plasticity (Kuenne et al. 2013, den Bakker et al.

2013). On the contrary, a study by Orsi et al. failed to find any evidence of spatial clustering in a

large number of genes which show evidence for recombination in L. monocytogenes (Orsi et al.

2008). Further, a recent study described the presence of homologous recombination in nearly

$60 \%$ of loci in the core genome of L. monocytogenes, although most of this variation was also

found to be affected by purifying selection and was thus neutral (Moura et al. 2016). This is

consistent with results from our analysis which finds linkage equilibrium between only $\sim 1 \%$ of

gene pairs in the genome. Also, genes considered as potential recombination hot spots (Table 2)

in our dataset are found to be scattered in the genome. A large number ( 41\%) of these "hot

spot” genes (Imo0046, Imo2624, Imo2856, Imo1469, Imo2616, Imo1816, Imo0248, Imo1335,

Imo2047, Imo2628, Imo2614), encode ribosomal proteins and their related subunits. According to the complexity theory (Jain et al. 1999), informational genes involved in complex biosystems

and maintenance of basal cellular functions are usually conserved, as they might be less likely to

be compatible in the systems of other species. Thus, housekeeping genes such as ribosomal

proteins are generally considered to be relatively restricted to horizontal gene transfer. However,

several reports suggest horizontal gene transfer of ribosomal proteins in many prokaryotic 
genomes (Brochier et al. 2000, Makarova et al. 2001, Garcia-Vallve et al. 2002, Chen et al. 2009). Two other "hot spot" genes (lmo0865, lmo2014) are involved in carbohydrate and amino

252 acid metabolism and have shown evidence for recombination in a prior study (Orsi et al. 2008),

253 indicating that the rapid diversification of these genes may enable L. monocytogenes to adapt to

254 environments with varying nutrient availabilities. Some of the other genes encode a variety of

255 internalin's (lmo0263, lmo0514, lmo0264, lmo0434), transporters (lmo0756, lmo1839),

256 transcriptional regulators (lmo0659), cell surface proteins (lmo2179), other invasion-associated

257 proteins (lmo0582), and proteins involved in response to temperature fluctuations (lmo1364,

258 Imo2206). Internalin's are cell surface proteins with known and hypothesized roles in virulence

259 (den Bakker et al. 2010, Tsai et al. 2011). Evidence of recombination in internalin's and these

260 other genes suggests that L. monocytogenes is subjected to sustained selection pleasures in the

261 environment, and it responds to these pressures by continuously regulating its transcriptional

262 machinery and remodeling the cell surface, thereby facilitating adaptation within the host and as 263 a saprophyte.

264 In conclusion, we have identified the presence of strong linkage disequilibrium in the

265 genome of L. monocytogenes. Parts of the genome showing strong non-random association

266 between genes are highly conserved regions, and are most possibly affected by positive

267 selection. The low levels of recombination within the L. monocytogenes genome suggests that

268 the patterns of association observed between genes can be used to recognize newly emerging

269 strains and help in understanding the processes involved in the diversification and evolution of $L$.

270 monocytogenes. Such investigations can ultimately help to develop better control measures for

271 this pathogenic microbe. 


\section{Acknowledgments}

274 We thank USDA and FSIS for providing us with Listeria monocytogenes whole-genome

275 sequencing samples from river water and effluents of poultry processing plants. The high-

276 performance computing cluster at Georgia Advanced Computing Resource Center (GACRC) at

277 the University of Georgia provided computational infrastructure and technical support

278 throughout the work. 


\section{References}

280 1) Zwick ME, Thomason MK, Chen PE, Johnson HR, Sozhamannan S, Mateczun A et al.

281 Genetic variation and linkage disequilibrium in Bacillus anthracis. Sci Rep. 2011;1: 169.

282 2) Yahara K, Didelot X, Jolley KA, Kobayashi I, Maiden MC, Sheppard SK et al. The

283 Landscape of Realized Homologous Recombination in Pathogenic Bacteria. Mol Biol Evol.

$284 \quad 2016 ; 33: 456-471$.

285 3) Feil EJ, Spratt BG. Recombination and the population structures of bacterial pathogens. Annu

286 Rev Microbiol. 2001;55: 561-590.

287 4) Steiner WW, Smith GR. Natural meiotic recombination hot spots in the Schizosaccharomyces

288 pombe genome successfully predicted from the simple sequence motif M26. Mol Cell Biol.

$289 \quad 2005 ; 25: 9054-9062$.

290 5) Smith JM, Smith NH, O'Rourke M, Spratt BG. How clonal are bacteria? Proc Natl Acad Sci

$291 \quad$ USA. 1993;90: 4384-4388.

292 6) Takuno S, Kado T, Sugino RP, Nakhleh L, Innan H. Population Genomics in Bacteria: A

293 Case Study of Staphylococcus aureus. Mol Biol Evol. 2012;29: 797-809.

294 7) Vigué L, Eyre-Walker A. The comparative population genetics of Neisseria meningitidis and

295 Neisseria gonorrhoeae. PeerJ. 2019;7: e7216. doi: 10.7717/peerj.7216.

296 8) Piffaretti JC, Kressebuch H, Aeschbacher M, Bille J, Bannerman E, Musser JM et al. Genetic

297 characterization of clones of the bacterium Listeria monocytogenes causing epidemic disease.

298 Proc Natl Acad Sci USA. 1989;86: 3818-3822.

299 9) Mallik S. IDENTIFICATION METHODS | Multilocus Enzyme Electrophoresis. In: Batt CA,

300 Tortorello ML, editors. Reference Module in Food Science: Encyclopedia of Food

301 Microbiology (Second Edition); 2014. Pp. 336-343. 
10) O'Rourke M, Stevens E. Genetic structure of Neisseria gonorrhoeae populations : a nonclonal pathogen. Journal of General Microbiology. 1993;139: 2603-2611.

11) Moura A, Criscuolo A, Pouseele H, Maury MM, Leclercq A, Tarr C et al. Whole genomebased population biology and epidemiological surveillance of Listeria monocytogenes. Nat Microbiol. 2016;2: 16185.

12) Wiedmann M, Bruce JL, Keating C, Johnson AE, McDonough PL, Batt CA. Ribotypes and Virulence Gene Polymorphisms Suggest Three Distinct Listeria monocytogenes Lineages With Differences in Pathogenic Potential. Infect Immun. 1997;65: 2707-2716.

13) Call DR, Borucki MK, Besser TE. Mixed-genome Microarrays Reveal Multiple Serotype and Lineage-Specific Differences Among Strains of Listeria monocytogenes. J Clin Microbiol. 2003;41: 632-639.

14) Ragon M, Wirth T, Hollandt F, Lavenir R, Lecuit M, Le Monnier A et al. A new perspective on Listeria monocytogenes evolution. PLoS Pathog. 2008;4(9): e1000146. doi:

$$
\text { 10.1371/journal.ppat.1000146. }
$$

15) den Bakker HC, Didelot X, Fortes ED, Nightingale KK, Wiedmann M. Lineage Specific

$$
\text { Recombination Rates and Microevolution in Listeria monocytogenes. BMC Evol Biol. }
$$

322 17) Orsi RH, Sun Q, Wiedmann M. Genome-wide analyses reveal lineage specific contributions 323 of positive selection and recombination to the evolution of Listeria monocytogenes. BMC $324 \quad$ Evol Biol. 2008;8: 233. 
325 18) Kuenne C, Billion A, Mraheil MA, Strittmatter A, Daniel R, Goesmann A et al. Reassessment

326 of the Listeria monocytogenes Pan-Genome Reveals Dynamic Integration Hotspots and

327 Mobile Genetic Elements as Major Components of the Accessory Genome. BMC Genomics.

$328 \quad 2013 ; 14: 47$

329 19) Nelson KE, Fouts DE, Mongodin EF, Ravel J, DeBoy RT, Kolonay JF et al. Whole Genome

330 Comparisons of Serotype $4 \mathrm{~b}$ and 1/2a Strains of the Food-Borne Pathogen Listeria

331 monocytogenes Reveal New Insights Into the Core Genome Components of This Species.

$332 \quad$ Nucleic Acids Res. 2004;32: 2386-2395.

333 20) Hain T, Chatterjee SS, Ghai R, Kuenne CT, Billion A, Steinweg C et al. Pathogenomics of

334 Listeria spp. Int J Med Microbiol. 2007;297: 541-557.

335 21) den Bakker HC, Cummings CA, Ferreira V, Vatta P, Orsi RH, Degoricija L et al.

336 Comparative genomics of the bacterial genus Listeria: Genome evolution is characterized by

337 limited gene acquisition and limited gene loss. BMC Genomics. 2010;11: 688.

338 22) den Bakker HC, Desjardins CA, Griggs AD, Peters JE, Zeng Q, Young SK et al. Evolutionary

339 Dynamics of the Accessory Genome of Listeria monocytogenes. PLoS One. 2013;8: e67511.

340 doi: 10.1371/journal.pone.0067511.

341 23) Cantinelli T, Chenal-Francisque V, Diancourt L, Frezal L, Leclercq A, Wirth T et al.

342 "Epidemic clones" of Listeria monocytogenes are widespread and ancient clonal groups. J

343 Clin Microbiol. 2013;51: 3770-3779.

344 24) Salcedo C, Arreaza L, Alcalá B, de la Fuente L, Vázquez JA. Development of a multilocus

345 sequence typing method for the analysis of Listeria monocytogenes clones. J Clin Microbiol.

$346 \quad 2003 ; 41: 757-762$. 
347 25) Louha S, Meinersmann RJ, Abdo Z, Berrang ME, Glenn TC. An open-source program

348 (Haplo-ST) for whole-genome sequence typing shows extensive diversity of Listeria

349 monocytogenes in outdoor environments and poultry processing plants. Appl Environ

350 Microbiol. 2020;87. DOI: 10.1128/AEM.02248-20

351 26) Excoffier L, Lischer HEL. Arlequin suite ver 3.5: A new series of programs to perform 352 population genetics analyses under Linux and Windows. Mol Ecol Resour. 2010;10: 564-567.

353 27) Ratan A. Assembly algorithms for next generation sequence data. Ph.D. Dissertation, The

354 Pennsylvania State University. 2009. Available from:

355 https://etda.libraries.psu.edu/files/final_submissions/587

356 28) Letunic I, Bork P. Interactive tree of life (iTOL) v3: an online tool for the display and

357 annotation of phylogenetic and other trees. Nucleic Acids Res. 2016; 44: W242-245.

358 29) Slatkin M. Linkage disequilibrium in growing and stable populations. Genetics. 1994;137:

$359 \quad 331-336$.

360 30) Charlesworth B, Charlesworth D. Elements of Evolutionary Genetics. Greenwood Village,

361 Colorado: Roberts and Company publishers; 2010.

362 31) Duncan KE, Ferguson N, Kimura K, Zhou X, Istock CA. Fine-scale genetic and phenotypic

363 structure in natural populations of Bacillus subtilis and Bacillus licheniformis: implications for

364 bacterial evolution and speciation. Evolution. 1994;48: 2002-2025.

365 32) Al Suwayyid BA, Coombs GW, Speers DJ, Pearson J, Wise MJ, Kahler CM. Genomic

366 epidemiology and population structure of Neisseria gonorrhoeae from remote highly endemic

367 Western Australian populations. BMC Genomics. 2018;19: 165.

368 33) Suerbaum S, Smith JM, Bapumia K, Morelli G, Smith NH, Kunstmann E et al. Free

369 recombination within Helicobacter pylori. Proc Natl Acad Sci USA. 1998;95: 12619-12624. 
370 34) Buchrieser C. Biodiversity of the species Listeria monocytogenes and the genus Listeria.

$371 \quad$ Microbes Infect. 2007;9: 1147-1155.

372 35) Nightingale K, Windham K, Wiedmann M. Evolution and molecular phylogeny of Listeria

373 monocytogenes isolated from human and animal listeriosis cases and foods. J Bacteriol.

$374 \quad 2005 ; 187: 5537-5551$.

375 36) Glaser P, Frangeul L, Buchrieser C, Rusniok C, Amend A, Baquero F et al. Comparative

376 genomics of Listeria species. Science. 2001;294: 849-852.

377 37) Borezee E, Msadek T, Durant L, Berche P. Identification in Listeria monocytogenes of MecA,

378 a homologue of the Bacillus subtilis competence regulatory protein. J Bacteriol. 2000;182:

$379 \quad 5931-5934$.

380 38) Jain R, Rivera MC, Lake JA. Horizontal gene transfer among genomes: the complexity

381 hypothesis. Proc Natl Acad Sci USA. 1999;96: 3801-3806.

382 39) Garcia-Vallve S, Simo FX, Montero MA, Arola L, Romeu A. Simultaneous horizontal gene

383 transfer of a gene coding for ribosomal protein 127 and operational genes in Arthrobacter sp. J

$384 \quad$ Mol Evol. 2002;55: 632-637.

385 40) Makarova KS, Ponomarev VA, Koonin EV. Two C or not two C: recurrent disruption of Zn-

386 ribbons, gene duplication, lineage-specific gene loss, and horizontal gene transfer in evolution

387 of bacterial ribosomal proteins. Genome Biol. 2001;2: RESEARCH 0033. doi: 10.1186/gb-

388 2001-2-9-research0033.

389 41) Chen K, Roberts E, Luthey-Schulten Z. Horizontal gene transfer of zinc and non-zinc forms

390 of bacterial ribosomal protein S4. BMC Evol Biol. 2009;9: 179.

391 42) Brochier C, Philippe H, Moreira D. The evolutionary history of ribosomal protein RpS14:

392 horizontal gene transfer at the heart of the ribosome. Trends Genet. 2000;16: 529-533. 
393 43) Meinersmann RJ, Phillips RW, Wiedmann M, Berrang ME. Multilocus sequence typing of

394 Listeria monocytogenes by use of hypervariable genes reveals clonal and recombination

395 histories of three lineages. Appl Environ Microbiol. 2004;70: 2193-2203.

396 44) Flamm RK, Hinrichs DJ, Thomashow MF. Introduction of pAM beta 1 into Listeria

397 monocytogenes by conjugation and homology between native L. monocytogenes plasmids.

$398 \quad$ Infect Immun. 1984;44: 157-161.

399 45)Hodgson DA. Generalized transduction of serotype 1/2 and serotype 4b strains of Listeria

$400 \quad$ monocytogenes. Mol. Microbiol. 2000;35: 312-323.

401 46) Lebrun M, Loulergue J, Chaslus-Dancla E, Audurier A. Plasmids in Listeria monocytogenes

402 in relation to cadmium resistance. Appl Environ Microbiol. 1992;58: 3183-3186.

403

404

405 Supporting information

406 S1 File. Panel of 180 L. monocytogenes isolates collected from different ecological communities.

407 S2 File. Whole-genome MLST profiles of the 180 L. monocytogenes isolates.

408 S3 File. Whole-genome MLST profiles of 2233 loci retained for AMOVA after filtering out

409 paralogous loci and loci with $>5 \%$ of missing data.

410 S4 File. Heatmap of LD in the genome of L. monocytogenes.

411 S5 File. Percentage of genes at LD with each gene in the genome of L. monocytogenes. 


\section{Locations}

Clinical

$\int$ Food

$\bigcirc$ FCS

RTE

C EFPP

$\bigcirc$ Milk

$\bigcirc$ Soil

C River

Panure

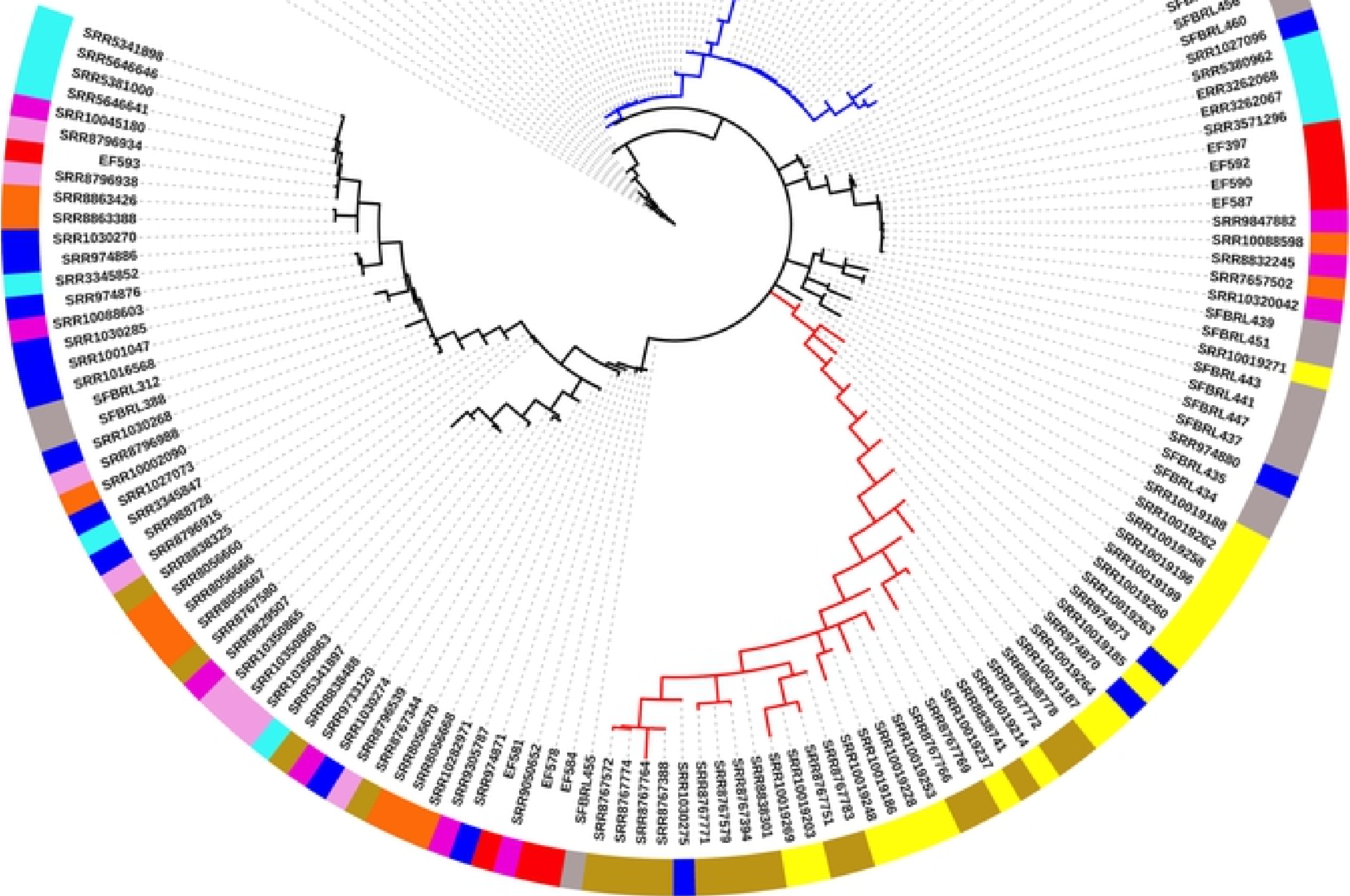

Figure 1 
bioRxiv preprint doi: https://doi.org/10.1101/2020.11.02.364679; this version posted November 2, 2020. The copyright holder for this preprint

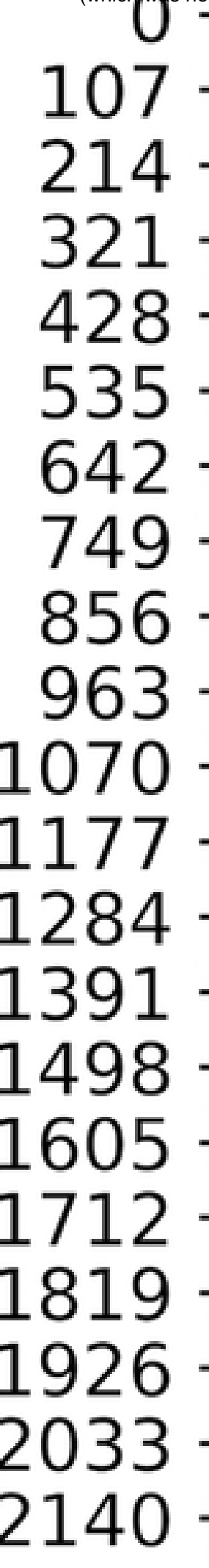
105 and is also made available for use under a CCO license.

-

(1)

๑

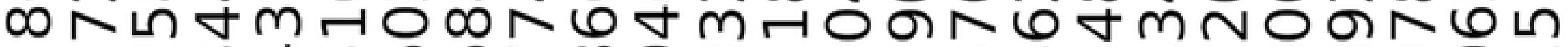
न म्नम

Figure 2 